\title{
Relationship between consultation length and rational prescribing of drugs in Gorgan city, Islamic Republic of Iran
}

\author{
V. Khori, ${ }^{7}$ S. Changizi, ${ }^{1}$ E. Biuckians, ${ }^{1}$ A. Keshtkar, ${ }^{2}$ A.M. Alizadeh, ${ }^{3}$ A.M. Mohaghgheghi ${ }^{3}$ and M.R Rabie ${ }^{4}$
}

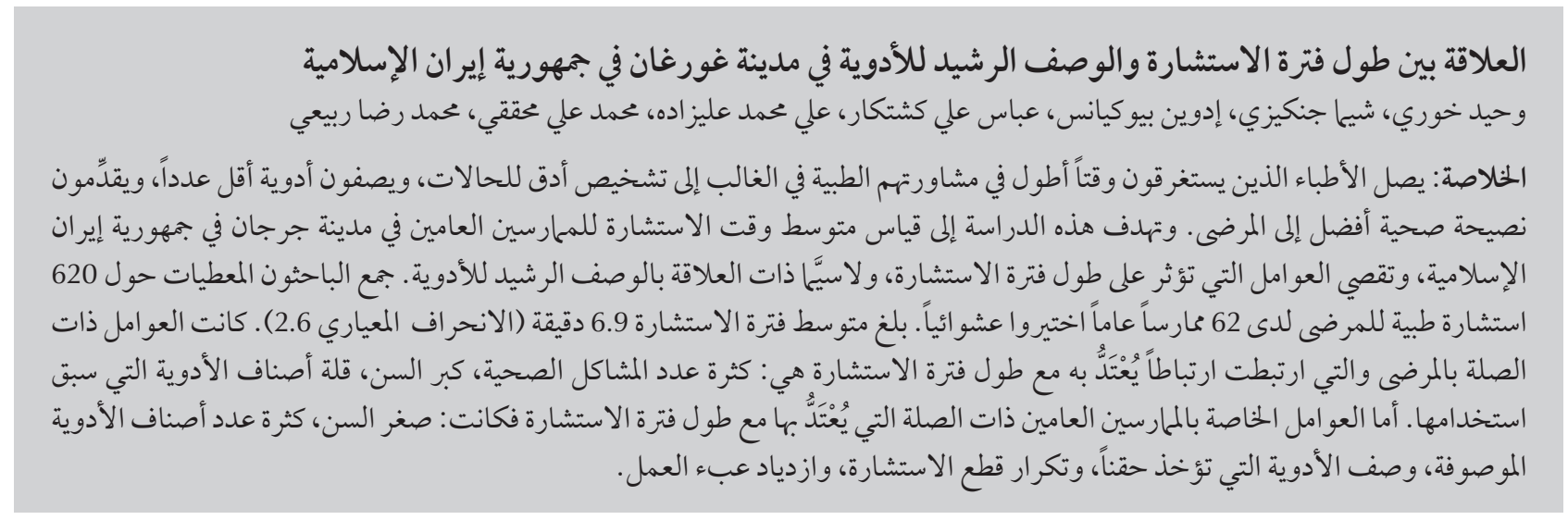

ABSTRACT Doctors with longer consultation times tend to diagnose illnesses more precisely, prescribe fewer drugs and present better health advice to their patients. The aim of this study was to measure the average consultation time of general practitioners in Gorgan, Islamic Republic of Iran and to investigate the factors affecting consultation length, especially in relation to rational prescribing of drugs. Data were collected on 620 patient consultations with 62 randomly selected general practitioners. Mean consultation length was 6.9 (SD 2.6) minutes. Patient factors that were significantly associated with a longer mean duration of consultation time were: higher number of health problems, older age and fewer items of previously used drugs. Physician factors that were significantly associated with a longer mean consultation time were: younger age, higher numbers of items prescribed and injectable drugs prescribed, frequency of interruptions and higher workload.

Relation entre la durée des consultations et la prescription rationnelle de médicaments dans la ville de Gorgan (République islamique d'Iran)

RÉSUMÉ Les médecins dont les consultations sont plus longues posent souvent des diagnostics plus précis, prescrivent moins de médicaments et offrent de meilleurs conseils en matière de santé à leurs patients. La présente étude visait à mesurer la durée moyenne de consultation des médecins généralistes à Gorgan (République islamique d'Iran), à rechercher les facteurs qui l'influencent, et à étudier la relation avec la prescription rationnelle de médicaments. Les données ont été recueillies auprès de 62 médecins généralistes sélectionnés aléatoirement et à partir de 620 consultations de patients. La durée moyenne de la consultation était de 6,9 minutes (E.T. 2,6). Les facteurs relatifs aux patients et qui étaient fortement associés à une durée moyenne supérieure de la consultation étaient les suivants : de nombreuses comorbidités, un âge avancé et un petit nombre de médicaments déjà utilisés. Les facteurs relatifs aux médecins et qui étaient fortement associés à une durée moyenne supérieure de la consultation étaient les suivants : un âge plus jeune, la prescription de traitements injectables et d'un grand nombre de médicaments, des interruptions fréquentes et une charge de travail élevée. 


\section{Introduction}

The effect of consultation time on care in general practice has been studied many times [1-13]. Doctors with longer consultation times tend to diagnose illnesses more precisely, prescribe fewer drugs and present better health advice to their patients [14-16]. Other studies have looked at correlations between aspects of the consultation process and the quantity and quality of prescribed drugs in each prescription [17-24]. In the Eastern Mediterranean region, short consultation times in general practice have been associated with a higher mean number of drugs prescribed $[2,3]$. Consultation time is affected by several factors including the physician, the patient, the reason for the encounter, the doctor-patient relationship, structural factors, geographical area and the health care system [4].

In Gorgon province of the Islamic Republic of Iran, nearly 98\% of patients are covered by government insurance, and due to the generic drug regulations in the country, there is no pressure from pharmaceutical companies to persuade physicians to buy brand-name products. Insurance companies pay for more than $65 \%$ of the drug cost of a prescription. There is therefore no direct relationship between the income of a physician and the number of items prescribed in a prescription. However, patients in Gorgan province have a tendency to receive more medicines at each visit than other provinces of the country [unpublished data]. The reasons for these differences may be due to sociocultural factors such as the multi-ethnic population living in Gorgan, the high proportion of uneducated and illiterate people, low incomes and use of self-medication. In view of the sociocultural and financial situation in Gorgan district, different results about factors affecting consultation time could be expected.

The aim of present study was to measure the average consultation time of general practitioners (GPs) in
Gorgan, Islamic Republic of Iran and to investigate the factors affecting consultation length, especially in relation to rational prescribing of drugs.

\section{Methods}

We performed a cross-sectional study in Gorgan district, during spring and summer 2007.

\section{Sample}

According to a preliminary study on the consulting time of 30 physicians, using a mean consultation time of 8 (SD 2) min. with $95 \%$ confidence we estimated that at least 620 consultations were required to meet the objectives of the study. According to the available data on the prescribing rate of GPs in Gorgan (registered by the government insurance company in Gorgan), the average daily number of patient visits to physicians was 10. From 190 GPs that were classified alphabetically, 62 GPs were selected (46 men and 16 women) using systematic random sampling. The first 10 patients arriving at the physician's office were selected consecutively for analysis and checklists were filled out for all of them.

\section{Data collection}

Two medical staff members were selected and trained by an internist and a pharmacologist during a 1-week period (4 sessions). Observers were employed by Golestan University of Medical Sciences. All observations were made by the same 2 observers. Doctors and patients were blind to the aims of this study but all of them gave consent to participate. The study was approved by the institutional ethical committee of Golestan University of Medical Sciences.

For the data collection one observer was located in the physician's room and was responsible for recording data about GPs. The other observer was located in the waiting room to fill out the patient questionnaire after the consultation. Children under 12 years old who attended with a parent were included in our study and the parent was requested to complete the questionnaire. The entry and exit times of patients to and from the GP's room was recorded using a stopwatch and was used to calculate the consultation time.

All variables studied were based on previous studies $[5,14,25]$ and on factors know to affect physicians' prescribing pattern in Gorgan district (sex, age, practice location and mean rate of drug prescribing) (unpublished data). For GPs, we considered the following independent variables: age and sex of physician, practice location, knowledge about patient's medical history, diagnosis (somatic, psychological or requirement for laboratory investigations), taking patient's drug history, number of drug items prescribed, number of injectable drugs prescribed and number of patients in waiting room (workload). For patients, the independent variables were: age, sex, reason for encounter (for prescription or for laboratory test follow-up), degree of satisfaction with the consultation (not satisfied, somewhat satisfied or completely satisfied), knowledge about use and precautions of drugs prescribed, tendency to expect a drug prescription [19], number of previously used drugs, frequency of interruptions to the consultation and number of health problems presented. Satisfaction and tendency to expect a drug prescription were assessed using methods described in previous studies $[5,24,26]$.

\section{Data analysis}

Data entry and analysis was done using SPSS, version 15. Data were analysed using descriptive statistics [percentage, mean and standard deviation (SD)], Mann-Whitney U-test and Kruskal-Wallis and linear regression. $P<0.05$ was considered as statistically significant. 


\section{Results}

\section{Characteristics of patients and physicians}

A total of 620 patients were studied: 323 (52.1\%) males and 297 (47.9\%) females. Patients were aged between 0 and 80 years, although the majority were between the ages of 29 to 35 years old and the mean age was 39.4 (SD 18) years.

There were $62 \mathrm{GPs}$ (46 men and 16 women) between the ages of 31 and 63 years old with a mean age of 43.7 (SD 9.6) years old. Most of the GPs practised in urban areas (80.6\%).

\section{Consultation time}

\section{Patient factors}

The total mean consultation time was 6.9 (SD 2.6) min, while the mean number of health problems presented were 1.8 (SD 0.8) and number of previously used drugs were 1.3 (SD 1.5). The mean consultation length for female patients was significantly longer than for male patients: 7.5 (SD 2.8) versus 6.3 (SD 2.2) $\min (P<0.001)$ (Table 1). Patients with fewer health problems had shorter mean consultation times: 5.4 (SD 1.5) min for patients who only complained about 1 health problem compared with 11.2 (SD 2.0) min for patients with 4 complaints/health problems. Consultation time was shorter for patients who attended only for a prescription (5.8 versus $7.1 \mathrm{~min}$ ) or only for laboratory tests follow-up (5.4 versus 7.0 $\mathrm{min}$ ). Consultation time increased with a higher self-reported expectation of patients for prescribed drugs (from 4.8 to $7.2 \mathrm{~min}$ ). Consultation time for patients who did not have a complete knowledge about the use and precautions of their prescribed drugs was shorter (6.4 versus $7.1 \mathrm{~min}$ ).
There was a direct relationship between the degree of patients' satisfaction and mean consultation time. Consultation length for patients completely satisfied with the consultation was $7.0 \mathrm{~min}$ but only $4.8 \mathrm{~min}$ for those who reported not being satisfied $(P<0.001)$ (Table 1).

\section{Physician factors}

There was no significant difference between the mean consultation times of male and female GPs (6.9 versus 6.9 min). Mean consultation time for GPs practising in the city was shorter than those in villages (6.7 versus $7.5 \mathrm{~min}$ ) $(P<0.001)$.

Knowing the patient's medical history decreased the consultation time significantly from 5.3 to $7.5 \mathrm{~min}(P<$ $0.001)$. When GPs recognized a psychological problem, mean consultation time increased to $12.8 \mathrm{~min}$ compared

\begin{tabular}{|c|c|c|c|c|}
\hline Variable & $\begin{array}{c}\text { No. of } \\
\text { consultations }\end{array}$ & $\%$ & $\begin{array}{c}\text { Consultation time (min.) } \\
\text { Mean (SD) }\end{array}$ & $\boldsymbol{P}$-value \\
\hline \multicolumn{5}{|l|}{ Patient's sex } \\
\hline Male & 323 & 52.1 & $6.3(2.2)$ & \multirow[t]{2}{*}{$<0.001$} \\
\hline Female & 297 & 47.9 & $7.5(2.8)$ & \\
\hline \multicolumn{5}{|l|}{ Reason for visit } \\
\hline \multicolumn{5}{|l|}{ For prescription } \\
\hline Yes & 126 & 20.3 & $5.8(2.5)$ & \multirow[t]{2}{*}{$<0.001$} \\
\hline No & 494 & 79.7 & $7.1(2.5)$ & \\
\hline \multicolumn{5}{|c|}{ For laboratory test follow-up } \\
\hline Yes & 63 & 10.2 & $5.4(2.1)$ & \multirow[t]{2}{*}{$<0.001$} \\
\hline No & 557 & 89.8 & $7.0(2.6)$ & \\
\hline \multicolumn{5}{|c|}{ Expectation of drug prescription } \\
\hline Not inclined & 7 & 1.1 & $4.7(0.8)$ & \multirow{3}{*}{$<0.001$} \\
\hline Somewhat inclined & 29 & 4.7 & $5.8(2.2)$ & \\
\hline Completely inclined & 520 & 83.9 & $7.2(2.5)$ & \\
\hline \multicolumn{5}{|c|}{ Knowledge about use and precautions of prescribed drugs } \\
\hline Somewhat & 28 & 4.5 & $6.4(2.7)$ & \multirow[t]{2}{*}{$>0.09$} \\
\hline Yes completely & 528 & 85.2 & $7.1(2.5)$ & \\
\hline \multicolumn{5}{|c|}{ Degree of satisfaction with consultation } \\
\hline Not satisfied & 5 & 0.8 & $4.8(0.9)$ & \multirow{3}{*}{$<0.001$} \\
\hline Somewhat satisfied & 27 & 4.4 & $5.1(1.1)$ & \\
\hline Completely satisfied & 588 & 94.8 & $7.0(2.6)$ & \\
\hline
\end{tabular}

$S D=$ standard deviation 
with only $6.5 \mathrm{~min}$ for a somatic problem $(P<0.001)$. Deciding to request laboratory tests decreased the mean consultation time to $5.5 \mathrm{~min}(P<0.001)$. Taking the patient's medical and drug history was associated with longer consultation times $(7.1$ versus $4.5 \mathrm{~min})(P<0.001)$ (Table 2).

The mean number of drug items prescribed in each consultation was 3.2 (SD 0.7) (median 3) and of injectable drugs was 0.2 (SD 0.4). The mean number patients in the waiting room (a measure of workload) was 4.4 (SD 1.8) and the mean number of interruptions to the consultation were 0.7 (SD 0.7). When doctors did not prescribe any drugs, the mean consultation time was shorter, at 5.2 (SD 2.3) min [median 5 min, $95 \%$ confidence interval: $4.6-5.8$.

\section{Factors affecting consultation time: linear regression analysis}

In multivariate linear regression analysis, patient factors that were was significantly associated with a longer mean duration of consultation time were: higher number of health problems, older age and fewer items of previously used drugs (Table 3). Physician factors that were significantly associated with a longer mean consultation time were: younger age, higher numbers of items prescribed and injectable drugs prescribed, frequency of interruptions and number of patients in the waiting room.

\section{Discussion}

\section{Statement of principal findings}

Consultation times were low and prescribing quality was poor in Gorgan, similar to data from many other countries in the Middle East and Asia $[1-3,26]$. For example, the mean consultation times in other Asian countries were 1.8 min in Pakistan, 6.6 min in Qatar and $2.3 \mathrm{~min}$ in Bangladesh. Among several determinant factors we showed that physician factors significantly affecting consultation length were physician's age, urban/rural location, taking patient's medical/drug history and type of diagnosis. Significant patient factors were age, sex, tendency to expect a drug prescription and number of health problems.
One limitation of our study is that we ignored some confounding factors related to physicians, such as income and employment, so we cannot easily generalize our findings to other physicians. In addition, the presence of an observer recording notes in the GP's office during the consultation might have influenced the doctor's behaviour and this could bias our study findings. The relationship between quality of consultations and average consultation time was not measured in this study, although patient satisfaction was assessed. On the other hand, determining the relationships between consultation time and factors related to drug prescriptions may be a strength of our study. We measured patient and physician parameters directly and indirectly with observers in order to eliminate patient bias related to physicians.

\section{Comparison with other studies}

\section{Consultation length}

The main finding of this study was the short mean consultation length (6.9 min.) for GPs in this location in the

\begin{tabular}{|c|c|c|c|c|}
\hline Variable & $\begin{array}{c}\text { No. of } \\
\text { consultations }\end{array}$ & $\%$ & $\begin{array}{c}\text { Consultation time (min.) } \\
\text { Mean (SD) }\end{array}$ & $P$-value \\
\hline \multicolumn{5}{|l|}{ Physician's sex } \\
\hline Male & 460 & 74.2 & $6.9(2.5)$ & \multirow[t]{2}{*}{$>0.5$} \\
\hline Female & 160 & 25.8 & $6.9(2.6)$ & \\
\hline \multicolumn{5}{|l|}{ Practice location } \\
\hline Urban & 500 & 80.6 & $6.7(2.6)$ & \multirow[t]{2}{*}{$<0.001$} \\
\hline Rural & 120 & 19.4 & $7.5(2.0)$ & \\
\hline \multicolumn{5}{|l|}{ Knew patient's medical history } \\
\hline Yes & 173 & 27.9 & $5.3(2.2)$ & \multirow[t]{2}{*}{$<0.001$} \\
\hline No & 447 & 72.1 & $7.5(2.4)$ & \\
\hline \multicolumn{5}{|l|}{ Diagnosis } \\
\hline Psychological & 8 & 1.3 & $12.8(3.2)$ & \multirow{3}{*}{$<0.001$} \\
\hline Somatic & 541 & 87.3 & $6.5(2.0)$ & \\
\hline Requirement for laboratory tests & 36 & 5.8 & $5.5(1.4)$ & \\
\hline \multicolumn{5}{|l|}{ Took medical and drug history } \\
\hline Yes & 568 & 91.6 & $7.1(2.5)$ & \multirow[t]{2}{*}{$<0.001$} \\
\hline No & 52 & 8.4 & $4.5(2.1)$ & \\
\hline
\end{tabular}

$S D=$ standard deviation . 


\begin{tabular}{|c|c|c|c|c|c|}
\hline Variable & B & SE & Beta & $t$ & $P$-value \\
\hline Constant & 3.00 & 0.45 & & 6.72 & $<0.001$ \\
\hline \multicolumn{6}{|l|}{ Patient variables } \\
\hline Age & 0.03 & 0.00 & 0.24 & 8.15 & $<0.001$ \\
\hline No. of health problems & 1.43 & 0.09 & 0.49 & 16.62 & $<0.001$ \\
\hline No. of previously used drugs & -0.29 & 0.05 & -0.17 & -5.25 & $<0.001$ \\
\hline \multicolumn{6}{|l|}{ Physician variables } \\
\hline Age & -0.03 & 0.01 & -0.12 & -4.24 & $<0.001$ \\
\hline No. of drugs prescribed & 0.49 & 0.10 & 0.15 & 4.90 & $<0.001$ \\
\hline No. of injectable drugs prescribed & 0.03 & 0.15 & 0.05 & 2.03 & 0.043 \\
\hline No. of patients in waiting room & -0.11 & 0.04 & -0.08 & -3.25 & $<0.001$ \\
\hline Frequency of interruptions to consultation & 1.06 & 0.09 & 0.30 & 11.66 & $<0.001$ \\
\hline
\end{tabular}

Model: $F=131.4$, degree of freedom $=8, P<0.001$. Predictors: (constant), physician's age, number of patients in waiting room, injectable drugs, frequency of interruptions, number of previously used drugs, number of health problems, patient's age, number of prescribed drugs.

$B=$ raw score regression coefficient; $S E=$ standard error of $B$; beta $=$ standardized regression coefficient; $t=t$-value for $B$ ( $B$ divided by $S E$ ).

Islamic Republic of Iran. Although consultation time in our study was shorter than in several other developed and developing countries $[5,15,16,23,25]$, knowledge about the use and precautions of prescribed drugs and satisfaction of patients was comparable with some other countries $[1-3,26]$. Others have suggested that while consultation time is an important indicator of quality of care the impact of cultural and sociopsychological factors should not be underestimated in determining patient satisfaction and quality of health care services $[13,27,28]$.

\section{Physician factors that influenced con- sultation time}

When we analysed the characteristics of GPs, we found that consultation time for rural GPs was longer than those practising in urban areas. This is contrary to the findings of Deveugele et al. [5], perhaps because the presence of more psychosocial problems (e.g. addiction), self-therapy and delay in submission, complicated patients with several diseases and lower workload (as measured in the waiting room) caused longer consultation times among rural patients our study.

Deveugele et al. and Howie et al. showed that consultations for psychological problems had a direct effect on consultation length $[5,25]$. Our study also showed that consultation time for patients diagnosed with psychological problems was considerably longer than for those with somatic (nonpsychological) problems. The most prevalent psychological problems in the Gorgan region are opium addiction and depression [29].

When our GPs requested laboratory tests, the average consultation time was lower. This is consistent with the findings of Hull and Hull [30] and Camasso and Camasso [31]. In rural areas, from an economic point of view, patients may prefer to use medication instead of travelling to the laboratory so the rate of prescribing laboratory tests is usually lower and consultation times are longer in rural regions than urban areas.

There was a positive relationship between GPs recording a patient's medical and drug history and longer consultation times in our study, a finding that is consistent with Deveugele et al.'s [5] and other studies [30,31]. Complaints about a new problem will force GPs to make more investigations and so lengthen the consultation time. Despite the absence of a comprehensive family practice health care system in Gorgan, the low cost of physicians' fees and drugs may result in frequent visits of patients to the same physician.
Doctors are usually therefore aware of their patients' medical and drug history and this can explain the relatively short consultation times in Gorgan.

We found that there was no significant difference between the consultation times of male and female GPs. Deveugele et al. also found that the sex of the doctor did not influence consultation time [5]. This is surprising as female patients in our study had longer mean consultation times than men and if women in Islamic Republic of Iran had a preference to be seen by a female physician we might have expected that the consultation time for female GPs would also be longer than for male GPs. We can explain this by the smaller number of female physicians in the sample.

Our finding that consultation length was longer for younger GPs agrees with Deveugele et al. [5] but contradicts a previous study showing that older physicians had longer consultations [4]. More research would be needed into this aspect of consultation length.

There was a direct correlation between the number of items prescribed and consultation length. The prescribing rate and mean number of prescribed drugs was much higher in Gorgan compared with previous studies in other countries (Figure 1) [4,32-38]. In the United Kingdom, however, Howie et al. 
Inside of Iran (IR)

Outside of Iran (IR)

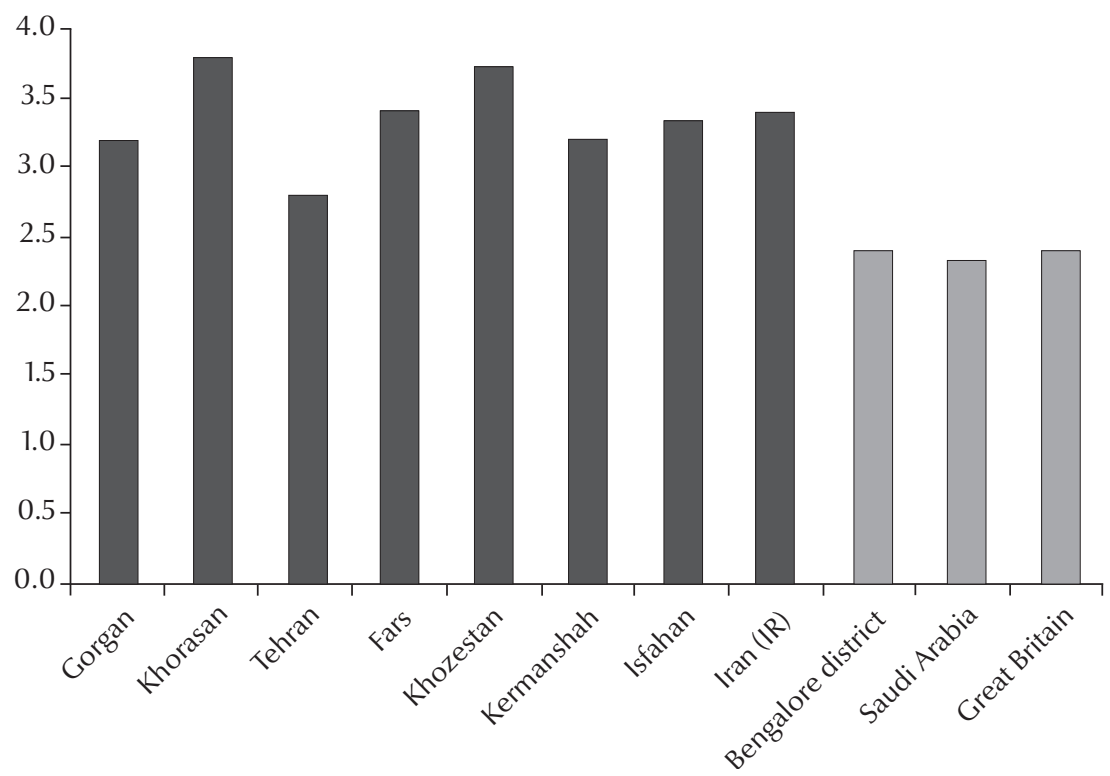

Figure 1 Mean number of drugs prescribed in consultations in the Islamic Republic of Iran and other countries

found higher rates of prescribing by physicians with shorter consultation times [32], and Hartzema and Christensen showed a direct relationship between prescribing volume and shortness of consultation time [39]. Among several factors that might explain this controversy are the lower cost of drugs in the Islamic Republic of Iran, the consequences of self-medication, more complicated cases and more interruptions by patients.

\section{Patient factors that influenced consultation time}

Consistent with the results of other studies, we showed that consultation length was correlated with patient's sex, with women having longer consultations $[4,5,25]$. The reason for the visit was also a factor, with consultations for prescriptions and laboratory test followups being shorter and this also agrees with other research $[4,5,25]$.

There was a direct relationship between patients' tendency to expect a drug prescription and consultation length. More patients in our study expected a prescription (84\%) than in comparable studies in Europe; for example, according to Himmel et al. less than half of patients (46.5\%) expected a drug prescription from their doctor [40]. This may put pressure on physicians to consult longer in order to improve patients' drug information and increase their satisfaction. Such influences were not evident in Howie at al.'s study in the United Kingdom [25]. However, as mentioned by previous researchers, accurate assessments of the relationship between patients and physicians is difficult and needs further investigation [19-21].

Our study showed that there was a direct and significant relationship between patient satisfaction and consultation time and this agrees with previous studies in other countries $[14,27,31,33]$. Despite this, we cannot ignore the possible influence of cultural and socioeconomic factors on patient satisfaction in Gorgan. As stated before, the factors influencing patient satisfaction are complex and require further research $[26,41]$.

More objective patient factors that affected consultation time were in agreement with the results of other studies $[5,25]$ : age, number of health problems and number of previously used drugs. Among these, the number of health problems had a greater impact on consultation time compared with these other studies.

\section{Unanswered questions and future research}

For comparative purposes, it is suggested that this survey be repeated in other provinces of the Islamic Republic of Iran and nationwide. Performing this study for different specialties of physician may also result in interesting findings. A study about the influence of waiting time on patient satisfaction may be useful. A more complete investigation about relationships between drug interactions and adverse effects and consultation time may be needed.

\section{Acknowledgements}

The authors are deeply grateful to all the GPs who took part in this study and to Golestan University of Medical Sciences for organizational support.

\section{References}

1. Voo YO. Consultation length and case mix in a general practice clinic. Singapore Medical Journal, 1999, 40:13-17.

2. Hafeez A et al. Prescription and dispensing practices in public sector health facilities in Pakistan. Journal of the Pakistan Medical Association, 2004, 54:187-191.
3. Bener A et al. Do minutes count for health care? Consultation length in a tertiary care teaching hospital and in general practice. Middle East Journal of Family Medicine, 2007, 5(1)3-8.

4. Petek Ster $\mathrm{M}$ et al. Factors related to consultation time: experience in Slovenia. Scandinavian Journal of Primary Health Care, 2008, 26:29-34. 
5. Deveugele $\mathrm{M}$ et al. Consultation length in general practice: cross sectional study in six European countries. British Medical Journal, 2002, 325:1-6.

6. Cape J. Consultation length, patient-estimated consultation length, and satisfaction with the consultation. British Journal of General Practice, 2002, 52:1004-1006.

7. Graffy J. Patient choice in a practice with men and women general practitioners. British Journal of General Practice, 1990, 40:13-15.

8. Ogden J et al. "I want more time with my doctor": a quantitative study of time and the consultation. Family Practice, 2004, 21:479-483.

9. Andersson SO, Mattsson B. Features of good consultation in general practice: is time important? Scandinavian Journal of Primary Health Care, 1994, 12:227-232.

10. Dugdale DC, Epstein R, Pantilat SZ. Time and the patientphysician relationship. Journal of General Internal Medicine, 1999, 14:34-40.

11. Lussier MT, Richard C. Communication tips. Time flies: patients' perceptions of consultation length and actual duration. Canadian Family Physician Medecin de Famille Canadien, 2007, 53:46-47.

12. Hutton C, Gunn J. Do longer consultations improve the management of psychological problems in general practice? A systematic literature review. BMC Health Services Research, 2007, 7:71.

13. Grol R et al. Patients' priorities with respect to general practice care: an international comparison. European Task Force on Patient Evaluations of General Practice (EUROPEP). Family Practice, 1999, 16:4-11.

14. Wilson A, Childs S. The relationship between consultation length, process and outcomes in general practice: a systematic review. British Journal of General Practice, 2002, 52:1012-1020.

15. De Silva N. The consultation and doctor-patient communication. Ceylon Medical Journal, 1999, 44:28-31.

16. Wilson A et al. Health promotion in the general practice consultation: a minute makes a difference. British Medical Journal, 1992, 304:227-230.

17. Stevenson FA et al. Doctor-patient communication about drugs: the evidence for shared decision making. Social Science and Medicine, 2000, 50:829-840.

18. Howie JG, Porter AM, Forbes JF. Quality and the use of time in general practice: widening the discussion. British Medical Journal, 1989, 298:1008-1010.

19. Stevenson FA et al. GPs' perceptions of patient influence on prescribing. Family Practice, 1999, 16:255-261.

20. Cockburn J, Pit S. Prescribing behaviour in clinical practice: patients' expectations and doctors' perceptions of patients' expectations--a questionnaire study. British Medical Journal, 1997, 315:520-523.

21. Britten N, Ukoumunne O. The influence of patients' hopes of receiving a prescription on doctors' perceptions and the decision to prescribe: a questionnaire survey. British Medical Journal, 1997, 315:1506-1510.

22. Lundkvist J et al. The more time spent on listening, the less time spent on prescribing antibiotics in general practice. Family Practice, 2002, 19:638-640.
23. Britt H, Valenti L, Miller G. Time for care. Length of general practice consultations in Australia. Australian Family Physician, 2002, 31:876-880.

24. Little $\mathrm{P}$ et al. Importance of patient pressure and perceived pressure and perceived medical need for investigations, referral, and prescribing in primary care: nested observational study. British Medical Journal, 2004, 328:444.

25. Howie JGR et al. Quality at general practice consultations: crosssectional survey. British Medical Journal, 1999, 319:738-743.

26. Mendoza Aldana J, Piechulek H, Al-Sabir A. Client satisfaction and quality of health care in rural Bangladesh. Bulletin of the World Health Organization, 2001, 79:512-517.

27. Freeman GK et al. Evolving general practice consultation in Britain: issues of length and context. British Medical Journal, 2002, 324:880-882.

28. Campbell JL, Ramsay J, Green J. Age, gender, socioeconomic and ethnic differences in patients' assessments of primary health care. Quality in Health Care, 2001, 10:90-95.

29. Mohammadi MR et al. An epidemiological study of psychiatric disorders in Golestan province, 2001. Journal of Gorgan University of Medical Sciences, 2004, 6(1):67-77.

30. Hull FM, Hull FS. Time and the general practitioner: the patient's view. Journal of the Royal College of General Practitioners, 1984, 34:71-75.

31. Camasso MJ, Camasso AE. Practitioner productivity and the product content of medical care in publicly supported health centres. Social Science \& Medicine, 1994, 38:733-748.

32. Howie JG et al. Long to short consultation ratio: a proxy measure of quality of care for general practice. British Journal of General Practice, 1991, 41:48-54.

33. Hughes D. Consultation length and outcome in two group general practices. Journal of the Royal College of General Practitioners, 1983, 33:143-147.

34. Cheraghali AM, Idries AM. Availability, affordability, and prescribing pattern of medicines in Sudan. Pharmacy World and Science, 2009, 31(2):209-215

35. Safaeian L. et al. General physicians and prescribing pattern in Isfahan, Iran. Oman Medical Journal, 2011, 26(3):205-206.

36. Srishyla MV et al.. A comparative study of prescribing pattern at different levels of health care delivery system in Bangalore district. Indian Journal of Physiology and Pharmacology, 1995, 39(3):247-251.

37. Neyaz $\mathrm{Y}$ et al. [Medication prescribing pattern in primary care in Riyadh City, Saudi Arabia]. Eastern Mediterranean Health Journal, 2011, 17(2):149-155 [in Arabic].

38. Damanhori AH et al. Diurnal variation of prescribing pattern of primary care doctors in Bahrain. Journal of Evaluation in Clinical Practice, 2007, 13(1):25-30.

39. Hartzema AG, Christensen DB. Non-medical factors associated with the prescribing volume among family practitioners in an HMO. Medical Care, 1983, 21:990-1000.

40. Himmel $W$ et al. Are patients more satisfied when they receive a prescription? The effect of patient expectations in general practice. Scandinavian Journal of Primary Health Care, 1997, 15(3):118-122

41. Mansour AA, Al-Osimy MH. A study of satisfaction among primary health care patients in Saudi Arabia. Journal of Community Health, 1993, 18:163-173. 